Arte y museos

del siglo $\mathrm{xxI}$

Entre los nuevos ámbitos
y las inserciones tecnologicas

y las inserciones

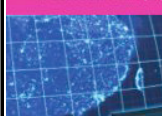

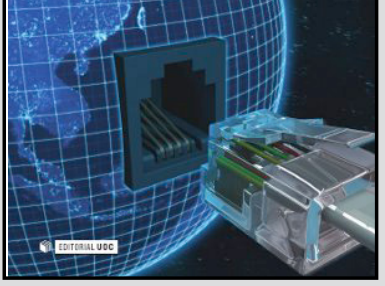

Arte y museos del siglo XXI. Entre los nuevos ámbitos y las inserciones tecnológicas

María Luisa Bellido Gant (ed.)

Editorial UOC - Acción Cultura / Museos y

patrimonio, Barcelona 2013

\title{
¿Hacia dónde caminan nuestros museos? Futuros pasos para el siglo XXI
}

L

os espacios expositivos en la actualidad sufren una mudanza que afecta a su concepción, aportando nuevos enfoques de lo que considerábamos como museo, así como en su discurso expositivo convencional. Esto mismo es lo que María Luisa Bellido Gant ha tenido en cuenta a la hora de editar este libro, que recoge los contenidos más punteros a nivel internacional en lo que a éstos ámbitos se refiere. Esta razón constituye uno de los firmes pilares que llevan a prestar especial atención al lector cuyo interés en obtener una visión reciente y aproximada a las nuevas tendencias museológicas, obliga a no obviar este compendio.

\section{El quid de lo tecnológico en arte y museos}

El objeto museable ha abierto un amplio espectro albergando nuevos ítems no convenciones como son la fotografía, estudiada por Patricia Méndez (CONICET, Argentina); el cine, que centra el trabajo de Mercedes Iánez (UGR); la propia arquitectura, reflejada en el capítulo de Renata Riberio dos Santos (UGR); o el patrimonio inmaterial abarcado por Victoria Pontes (UGR). Su presencia en los 
espacios expositivos conlleva cierta problemática y puntos de vista que convienen ser tenidos en cuenta. También asistimos a nuevas concepciones que se refieren a la musealización del territorio y que son recogidas en el epígrafe de $\mathrm{M}^{\mathrm{a}}$ Luisa Bellido (UGR). Estos planteamientos, suponen afrontar nuevas prácticas, no siempre en conocimiento de los profesionales en el sector, y que requieren un estudio particularizado y ajeno a las tipologías tradicionales.

Por su parte, los espacios expositivos cuentan con las nuevas tecnologías como aliados en la consecución de sus funciones, especialmente las dedicadas a la difusión y transmisión del conocimiento y el objeto cultural. Es esta nueva dinámica la que también cuenta con aportaciones importantes por parte de especialistas en el sector, como Isidro Moreno (UCM), que nos habla de los tipos de interactividad; o la web social o 2.0 a cargo de Nuria Rodríguez (UMA). La propiedad colectiva de los bienes o los nuevos recursos educativos vienen a ser reseñados por Anabel Fernández (UGR), mientras que la accesibilidad física queda recogida en el capítulo de Rocío Torres (UGR). Todos los textos pretenden poner en relieve las nuevas aportaciones e implicaciones que supone el uso de las nuevas tecnologías, tanto desde la institución como por parte del público, pero también de los inconvenientes y causas del no-aprovechamiento por parte de los mismos.

La praxis artística también ha tenido en cuenta nuevos lenguajes tecnológicos que comienzan a tener una consideración dentro de este campo, así como el uso de nuevas herramientas y soportes que se encuadran en el mundo digital y virtual. Términos como mobil media art o social art son analizados por Soledad Gómez (mediamusea.com), así como el net.art es tomado en consideración por Laura Baigorri (UB); o el AR Art, arte con realidad aumentada, que tiene cabida en el apartado de David Ruiz (UFES). Junto a otras prácticas como el video-mapping, estudiado por Lara F. Portolés (UOC), o el videojuego como arte, presentado por Ximena Hidalgo (UGR), resultan aún poco conocidas en nuestra sociedad y sin embargo su presencia queda bien constatada en los diferentes capítulos. Éstas nuevas tendencias constituyen la verdadera vanguardia artística de nuestro presente, encontrándonos en los prolegómenos de la creación de un arte con entidad propia. 
Finalizando, en Arte y museos del siglo XXI: entre los nuevos ámbitos y las inserciones tecnológicas podríamos afirmar que asistimos a un cóctel renovador en la materia cuya vigencia se desarrolla a la par que la redacción de sus páginas, ofreciendo consideraciones y reflexiones que colaboran a comprender su validez y permanencia en futuras décadas.

David Ruiz Torres

Doctor en Historia del Arte, Universidad de Granada - UGR Pos-doctorado en Artes, Universidade Federal do Espirito Santo - UFES 